\title{
La bioeconomía como herramienta para el crecimiento económico sostenible
}

Manuel Lainez ${ }^{1}$

Autor de Correspondencia: manuel@lainezbtc.com

\section{Resumen:}

El desarrollo tecnológico ha permitido diversificar los productos obtenidos en el marco de la bioeconomía, desde los alimentos, los productos forestales, los textiles y la energía, hasta los extractos y compuestos activos y una amplia gama de bioproductos. El nuevo contexto socioeconómico, en el que es imprescindible descarbonizar la economía o promover la economía circular, ha impulsado el desarrollo de la bioeconomía circular, especialmente en el marco del nuevo marco del Green Deal de la Unión Europea. La utilización de las biomasas generadas en España, especialmente las residuales procedentes del ámbito agroalimentario, del forestal, del urbano, tanto de los RSU como de los lodos de depuradora, son una oportunidad para el desarrollo económico. Las tecnologías que se están desarrollando permiten obtener compuestos químicos básicos, combustibles, biopolímeros, o compuestos con distintos tipos de actividad y funcionalidad, que pueden ser las materias primas para una nueva actividad económica. Se analizan los retos y las oportunidades para el desarrollo de la bioeconomía en España, así como la necesidad de realizar un análisis del ciclo de vida de cualquiera de los productos que se vayan a poner en el mercado, tanto los que vayan al consumidor final como los que se suministren a los sectores industriales. Los sectores industriales tradicionales como el de la energía, el de la gestión de residuos, el textil, el de la construcción, el del envase y embalaje, el de los vehículos a motor o el de la maquinaria y equipos, pueden suponer una oportunidad de negocio para las actividades ligadas a la bioeconomía, a través de la obtención de bioproductos.

Palabras clave: Bioeconomía circular, bioproductos, sectores industriales, Pacto Verde

\section{The bioeconomy as a tool for sustainable economic growth}

\author{
Manuel Lainez ${ }^{1}$
}

\section{Abstract:}

Technological development has made it possible to diversify the products obtained in the framework of the bioeconomy, from food, to forest products, textiles, energy, extracts, active compounds and a wide range of bioproducts. The new socio-economic context, in which it is essential to decarbonize and promote the circular economy, has furthered the development of the circular bioeconomy, especially within the new framework of the European Union Green Deal. The use of biomass generated in Spain, especially residual biomass from the agri-food, forestry and urban spheres, both from MSW and sewage sludge, constitute an opportunity for economic development. The technologies that are being developed make it possible to obtain basic chemical compounds, fuels, biopolymers, and compounds apt for different types of activities and functions, potential raw materials for new economic activity. The challenges and opportunities

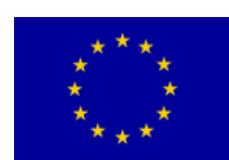

UNIÓN EUROPEA PROYECTO COFINANCIADO PROYECTO COFINANCIADO
POR EL FONDO EUROPEO DE
DESARROLIO REGIONAL DESARRO
(FEDER)

Una manera de hacer Europa

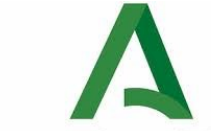

Junta de Andalucía
Andalucía

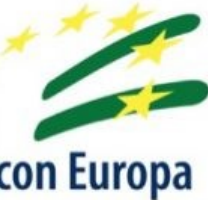


involved in the development of the bioeconomy in Spain are analyzed, as well as the need to carry out an analysis of the life cycle of the products that are going to be placed on the market, both those for end consumers and those supplied to industrial sectors. Traditional industrial sectors, such as energy, waste management, textiles, construction, packaging, motor vehicles, machinery and equipment, can represent opportunities for business for activities linked to the bioeconomy through the generation of bioproducts.

Key Words: Circular bioeconomy, bioproducts, industrial sectors, Green Deal

1 Director de Lainez Biotrends Consultoria Estratégica, (España), manuel@lainezbtc.com.

\section{INTRODUCCIÓN}

La bioeconomía engloba al conjunto de todas las actividades económicas relacionadas con la producción, transformación y utilización, directa o indirecta, de recursos de origen biológico. Consiste, según Ronzón et al (2020), en producir y transformar biomasa para el suministro de alimentos, piensos, materiales, energía y servicios relacionados con los ciudadanos.

Tradicionalmente englobaba la producción de alimentos, productos forestales, textiles y energía. Sin embargo, con el desarrollo de diferentes tecnologías el número de productos finales derivados han ido creciendo, por la vía de la obtención de extractos o compuestos activos, aplicados a la nutrición y la farmacia, o la transformación en biocompuestos diversos como podrían ser los bioplásticos o los biocombustribles.

La bioeconomía es una actividad importante en la Unión Europea y en España. De acuerdo con el Knowledge Bioeconomy Center (KBC, 2020), perteneciente al JRC, en 2017 empleó a alrededor de 17,5 millones de personas y generó aproximadamente 614.000 millones de euros de valor añadido. Esto representa alrededor del $8,9 \%$ de la población activa de la UE-27 y genera el 4,7\% del PIB de la UE-27. En España, de acuerdo con la misma fuente, generó en 2017 un volumen de ventas de 219 millones de $€$, que se corresponde con un valor añadido de 65 millones $€$. Además, dio empleo a 1,42 millones de personas. Por tanto, como país, representamos el $8 \%$ del empleo, el $10 \%$ de las ventas y el $11 \%$ del valor añadido de la bioeconomía comunitaria. 
En los últimos meses, en el marco de la arquitectura del Green Deal lanzado por la presidenta de la Comisión Europea, se considera que la bioeconomía circular constituye una pieza importante (Ronzón et al 2020). Este nuevo concepto surge de la interacción entre la bioeconomía y la economía circular, destacando como aspectos comunes la mejora del uso de los recursos y la ecoeficiencia, la reducción de la huella de carbono, la reducción de la demanda de carbono fósil, y la valorización de los residuos (Carrol y Dammer, 2018). No obstante, como recogen en su trabajo, la economía circular no está completa sin la bioeconomía y viceversa.

El Pacto Verde europeo se identifica por la Comisión Europea como la ruta para dotar a la UE de una economía sostenible, entendiendo que la realización de ese objetivo transformará los retos climáticos y medioambientales en oportunidades en todos los ámbitos políticos y que logremos una transición justa e integradora para todos (EU, 2020). En este artículo trataremos de demostrar por qué la bioeconomía está en el centro de esas nuevas políticas.

\section{EL CONTEXTO SOCIOECONÓMICO GLOBAL Y EUROPEO}

\subsection{Cambio climático}

A lo largo del siglo XX y en las dos últimas décadas estamos observando un incremento continuado de las temperaturas medias mundiales. Los años 2015 a 2018 han sido los cuatro años con temperaturas medias más elevadas desde que se dispone de registros y se hace una medición de estos. La temperatura media globa anual es hoy (UE, 2.019) $0,85^{\circ} \mathrm{C}$ más elevada que a finales del siglo XIX. Este hecho ya se analizó a principios de este siglo por Crowle (2000), concluyendo que el calentamiento durante el siglo pasado no tiene precedentes, y que solo alrededor del $25 \%$ del incremento podía ser atribuido a la variabilidad natural, mientras que el resto, la mayoría, se debía a los aumentos en los gases de efecto invernadero. 
Cramer et al (2018) han puesto en evidencia que en la ribera del mediterráneo la previsión, aceptada globalmente, de que el calentamiento a mediados de siglo puede provocar que la temperatura se eleve $2^{\circ} \mathrm{C}$ por encima de los niveles preindustriales, puede ser superada con muchas probabilidades. Este aumento de temperatura vendrá acompañado por fenómenos meteorológicos extremos como periodos más largos de sequías, concentración de la pluviometría e inundaciones, etc. Todas estas circunstancias tendrán un efecto devastador sobre la naturaleza y provocará cambios irreversibles en muchos ecosistemas, con la consiguiente pérdida de biodiversidad. También se traducirá en enormes costes para nuestra economía y mermará la capacidad de los países de producir alimentos.

\subsection{Economía circular}

El desarrollo económico mundial a lo largo de todo el siglo XX se ha producido en paralelo a una demanda creciente e ininterrumpida de recursos naturales: materiales de construcción, biomasas, combustibles de origen fósil y minerales de todo tipo, incluidos los industriales. Esa demanda acumulada ha iniciado un crecimiento superior al habitual, especialmente con el desarrollo económico de China, Brasil, México, etc. (Krausmann et al, 2009). Estos autores concluían con la necesidad de mejorar la eficiencia en el uso de las materias primas, desacoplando el crecimiento económico del consumo de materiales y de energía.

En caso de no abordarse alguna estrategia descarbonización, y de control de empleo de los recursos, los autores anteriores preveían un descenso alarmante de la biodiversidad y la naturaleza y, en el corto plazo, de algunos recursos como tierra, agua dulce, pesca, petróleo y gas de origen fósil, metales preciosos y de uso industrial, etc. Este mismo equipo, unos años más tarde, (Krausmann et al, 2017) concluyen que, para reducir la demanda futura de materiales y energía, y las emisiones de gases de efecto invernadero, será necesario desvincular los servicios de las existencias y los flujos de materiales 
mediante, por ejemplo, una utilización más intensiva de los recursos disponibles, una vida útil más prolongada y un diseño más eficiente.

De forma paralela a estos trabajos científicos, la Fundación Ellen Mc Arthur para la economía circular publicaba, en 2012, su documento "Hacia la economía circular" que se introducía con el siguiente texto: "ante los fuertes aumentos de la volatilidad en la economía mundial y los signos de agotamiento de los recursos, la justificación para un nuevo modelo económico es cada vez más fuerte. Muchos argumentan que es el momento adecuado para llevar este concepto de "economía circular" un paso más allá".

En estos años nuestra sociedad está avanzado desde una economía lineal, en la que extraemos materias primas para incorporarlas en los procesos productivos, obteniendo unos productos que van al mercado, de cuyos residuos nos deshacemos tras su utilización, a una economía del reciclado en la que tratamos de reutilizar una parte de los residuos de la cadena de producción y utilización, a una economía circular (Figura 1).

La transición de la economía lineal a la economía circular requiere reducir progresivamente la de recursos naturales e incrementar la utilización de recursos renovables. Comporta un enfoque diferente en cada una de las fases del proceso productivo y de vida útil de los productos. A continuación, resumimos algunos de los puntos esenciales (COM, 2020, 98 final):

- Obtención de materias primas: debe priorizarse la obtención de materias primas secundarias, es decir, aquellas que se obtienen a través de la recuperación de materiales y materias primas de los residuos generados en los procesos productivos

- Ecodiseño: es el diseño del producto desde su origen debe estar pensado para:

- maximizar su vida útil a través de la reparación y reutilización de productos que ya están siendo utilizados 
- facilitar la recuperación de materiales y materias primas una vez finalizada la vida útil del producto

- Producción: utilizando materias primas secundarias y minimizando tanto la de residuos como el consumo de materias primas

- Uso (vida útil): debe buscarse la máxima durabilidad del producto, facilitando su reparación y mantenimiento y su reutilización

- Tratamiento de los residuos: de enfocado a su reciclaje, facilitando su transformación en materiales y materias primas secundarias que originen un nuevo proceso productivo.

Figura 1. Diagrama de la economía circular. Fuente: UE.

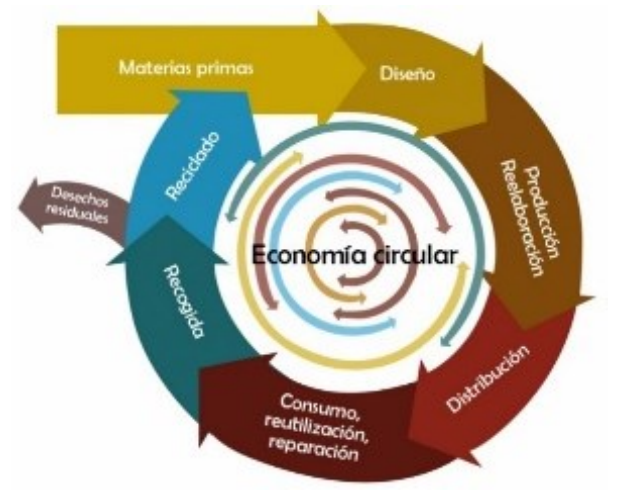

\subsection{Políticas europeas y españolas}

La Unión Europea, en el marco de su política de residuos, decidió modificar su estrategia de gestión, pasando de unas medidas basadas en la eliminación de los residuos y la valorización, a través del reciclado, a otra basada en prevenir la generación y en la preparación para su reutilización y reciclado. A finales de 2015 la Comisión Europea lanzó el Paquete de Economía Circular.

Buena parte de las 54 medidas de este paquete focalizaban la atención en cinco sectores de la economía: los plásticos, el sector agroalimentario, las materias primas críticas, el sector de la construcción y la demolición y el sector de la biomasa y los productos de base biológica. En cada uno de estos sectores se establecen unos objetivos generales, por fechas concretas, en los que obliga 
a los países a adoptar medidas concretas de recogida selectiva de residuos (urbanos, biológicos, textiles) y de cantidades recicladas (papel, cartón, vidrio, plásticos, etc).

La Unión Europea ha estado comprometida con los esfuerzos internacionales para enfrentar el cambio climático. A nivel europeo, se puso en marcha un paquete integral de medidas políticas para reducir las emisiones de gases de efecto invernadero a través del Programa Europeo de Cambio Climático (ECCP). En diciembre de 2019 la nueva Comisión Europea lanzó el Green Deal, como estrategia para responder a los retos climáticos y ambientales globales, para promover el crecimiento en una sociedad moderna, próspera, eficiente en el uso de los recursos y competitiva, climáticamente neutral en 2050 (COM 2019). Propone un conjunto de políticas transformadoras:

- Neutralidad climática en 2050, cuyo objetivo es reducir las emisiones entre $50-55 \%$ para 2030.

- Energía limpia, accesible y segura, promoviendo descarbonizar el sistema energético.

- Economía limpia y circular, basada en una nueva estrategia industrial orientada a desarrollar una actividad de bajas emisiones y con productos y servicios sostenibles, climáticamente neutros y circulares.

- Construcción y renovación y movilidad sostenible e inteligente.

- En el sistema sanitario se buscará la transición hacia la economía circular con sistemas de producción más eficientes, mejor almacenamiento y envasado, consumo saludable, reducción de las pérdidas y el desperdicio alimentario, transformación y transporte agrícola más sostenible y ciudadanos mejor informados.

- Preservar y restaurar los ecosistemas y el capital natural, basado en una nueva estrategia de biodiversidad, así como reducir la contaminación.

La economía circula se ha vuelto a impulsar en la Unión europea, específicamente, reformulando el paquete de economía circular (EIB, 2020). 
En España en junio de 2020 se adoptó la Estrategia Española de Economía Circular. Además, en los meses de junio y julio pasados se han presentado dos anteproyectos de Ley de Residuos y de Ley de Cambio climático. En el primer caso, al hablar de los biorresiduos, se establece la obligatoriedad de recogida separada para los municipios a partir de 2023. En el caso de los plásticos se prevé la prohibición de los de un solo uso a partir del 3 julio de 2021. El resto de los plásticos de un solo uso se deben reducir en un 50\% en 2026 y un $70 \%$ en 2030. En el segundo se proponen fechas y objetivos de reducción, similares a los europeos.

Todas estas políticas nos llevan a un escenario, a corto plazo, en el que va a ser necesario buscar el aprovechamiento integral de los recursos de origen biológico. Lo que hasta ahora eran subproductos o residuos deben valorizarse y transformarse en nuevos productos que vayan al mercado. De esta manera conseguimos tres objetivos de manera simultánea: mejoramos la eficiencia en los procesos productivos; alargamos la vida económica de los recursos naturales y reducimos la huella de carbono de todos los productos. Además, estamos promoviendo la sinergia industrial, generando nuevas cadenas de valor en la economía.

\section{LAS OPORTUNIDADES DE TRANSFORMACIÓN DE LA BIOMASA}

El lanzamiento de la estrategia europea de bioeconomía en 2012 desencadenó un conjunto de trabajos para cuantificar las posibilidades de esta nueva área del conocimiento y la economía. Para ello era imprescindible, como indicaban M' Barek et al (2014), generar un procedimiento y unas bases de datos que permitieran cuantificar la disponibilidad de biomasas en Europa. De hecho, este grupo del JRC publicaron el procedimiento de trabajo y el flujo de las biomasas en Europa (Gurria et al, 2017). Diferenciaban tres grandes grupos de residuos según su origen: biomasa agraria, pesquera y forestal.

En un trabajo posterior, del mismo grupo (Camia et al, 2018) señalaban que la agricultura genera $956 \mathrm{Mt}$ de biomasa, de las que el $46 \%$ era residual. Una parte de ella puede tener un valor económico (por ejemplo, cuando se utilizan 
para el lecho de animales o para la producción de bioenergía), aunque comentan que también es importante como proveedor de servicios ecosistémicos, al mantener los niveles de carbono orgánico en el suelo o prevenir su erosión. En el ámbito forestal recogen que el 32\% de la biomasa leñosa aérea total corresponde a ramas, tocones y copas en conjunto, denominadas otros componentes de la madera y que representan en torno a 95 Mt anuales. Otro ámbito descrito es la producción total de macro y microalgas fue de 0,23 Mt de masa húmeda en 2015 (que corresponde aproximadamente a 0,027 $\mathrm{Mt}$ de peso seco).

Thorenz et al (2018) realizaron una aproximación utilizando fuentes similares, cuantificando en $107 \mathrm{Mt}$ los residuos agrícolas en Europa. Sus resultados identifican a la paja de trigo como la fuente más prometedora en el sector agrícola, seguida del rastrojo de maíz, la paja de cebada y la paja de colza, que contienen una concentración total de lignocelulosa de más del $80 \%$ de materia seca. En el sector forestal, la corteza de residuos de dos especies de coníferas, el abeto y el pino, es la fuente más prometedora, con aproximadamente un $70 \%$ de lignocelulosa. También estimaron que solo un $8 \%$ de los residuos totales se estaban explotando.

Son más abundantes los trabajos que cuantifican las biomasas que pueden ser utilizada para su conversión en bioenergía que incorporan otros productos como los residuos sólidos urbanos o los lodos de depuradora. Algunos trabajos (Scarlat et al., 2018, o las propias publicaciones de la Comisión). El suministro de biomasa para bioenergía (es decir, energía primaria) en la UE alcanzó 140 Mt en 2016. De esta, el $96 \%$ fue procedente de la UE y el $4 \%$ restante se importó de países no pertenecientes a la UE. La biomasa procedente de la UE se transforma principalmente en energía en el Estado miembro en el que se produce, y solo el 7,2\% se convierte en energía en otro Estado Miembro.

Hamelin et al (2.019) han realizado un trabajo para estimar la producción de biomasas en la UE y ubicarlas geográficamente. Incluyen cuatro grandes actividades generadoras de biomasas: la agricultura (paja, estiércol, residuos 
de poda, plantaciones permanentes); la silvicultura (residuos forestales); el manejo de vegetación urbana (residuos de la gestión de áreas verdes urbanas y vegetación de caminos); y el desperdicio de alimentos (desperdicios de procesos alimentarios agroindustriales, incluyendo los residuos municipales biodegradables). En la Figura $n^{\circ} 2$ mostramos el resultado

En España podemos utilizar una combinación de trabajos a la hora de cuantificar las biomasas disponibles, entre los que destacamos los de IDAE (2011) y de BIOPLAT-SUSCHEM (2017), así como los datos del INE (2018) a la hora de cuantificar los lodos de depuradora. Dentro de las categorías de biomasas residuales podemos considerar los siguientes grupos:

- Biomasa agrícola residual, consistente en restos de cultivos como paja, tallos, hojas, ensilados, así como restos de podas, que alcanzarían una cifra de 30,5 $\mathrm{M \dagger}$

- Biomasa forestal, procedente de cultivos forestales (especies principalmente leñosas producidas mediante las actividades de cultivo en terreno forestal, cosecha y, en caso necesario, del procesado de las materias primas recolectadas; también se consideran los cultivos forestales no madereros, como plantas aromáticas o medicinales), de los aprovechamientos forestales (operaciones silvícolas en las masas forestales) o de los residuos forestales (limpieza y en el mantenimiento de las masas forestales y los espacios verdes), se evaluó en 18,7 Mt al año.

- Biomasas procedentes de los residuos de las producciones ganaderas, entre los que encontramos estiércoles y purines, camas para animales o gallinazas. Aunque en la actualidad tienen una demanda importante en el sector agrícola, especialmente los más sólidos, pueden ser destinados a su transformación. En España se cuantifican en 72 Mt al año.

- Biomasas residuales procedentes de la pesca y la acuicultura. No se cuantifican de forma separada en ninguno de los documentos que venimos utilizando como referencia.

- Hay unas biomasas especiales, procedentes de la cadena de valor cárnica, a las que habitualmente se les presta poca atención, por estar sometidas a 
una regulación compleja: son los Subproductos de Origen animal con destino distinto a la alimentación humana (SANDACH), que incluyen desde cadáveres de animales de las granjas hasta decomisos de los mataderos hasta subproductos de las industrias cárnicas. El volumen que se produce en nuestro país, y la riqueza en determinados ingredientes (grasas, proteínas, enzimas u hormonas), pueden hacer interesante su consideración. En España se producen al año 350 t de este grupo de subproductos.

- Biomasas residuales de la industria agroalimentaria, en las que se incluyen tanto productos no comestibles, como pieles, cáscaras o partes de pescados descartados, como productos que no llegan al mercado por no reunir los requisitos de higiene o calidad requeridos, como los residuos generados en los procesos productivos necesarios para la obtención de alimentos y bebidas (quesos, grasas, aceites, vino, cerveza, congelados, conservas, etc). en España se estimaba una producción de 83 Mt al año.

- Biomasas residuales de la industria de la madera, del papel y del sector textil, que se estiman, en España, en 6 Mt.

- Fracción fermentable de los residuos sólidos urbanos, que integraría todos los componentes orgánicos, que será obligatorio separar en nuestros municipios en 2023, así como los lodos de depuradora. En su conjunto representan en torno a $26 \mathrm{Mt}$ de productos.

- Los lodos de depuradora representaron en 2018 1,2 Mt de materia seca, que se gestionan mediante el uso agrícola el $87 \%$, la valorización energética el $5,5 \%$ y el depósito en vertedero el 7,5\%.

Por otra parte, las plataformas tecnológicas describen la potencialidad de la utilización de cultivos susceptibles de ser aprovechados para la obtención de biomasa, que la estiman en 39,4Mt. Los agrupan en herbáceos y leñosos. Los herbáceos se pueden clasificar, según el producto principal que se obtiene de ellos, en:

- Alcoholígenos. Especies utilizadas para la producción de bioetanol a partir de procesos de fermentación alcohólica de azucares simples. Comprenden tanto a los azucarados como a los amiláceos e insulínicos. 
- Lignocelulósicos. Especies herbáceas con alto contenido en lignocelulosa (celulosa, hemicelulosa y lignina) y de alta producción.

- Oleaginosos. Especies de las que se cosechan fracciones ricas en aceites (semillas o frutos), que se destinan a la producción de biodiesel y otros biocarburantes, así como otros productos (por ejemplo, para la fabricación de biopolímeros o la preparación de compuestos para cosmética).

Por otra parte, los cultivos leñosos pueden ser lignocelulósicos (la mayoría) o alcoholígenos.

El KBC (2020) ha publicado los flujos de la biomasa que forma parte de la bioeconomía. De acuerdo con esa información, en España se producen anualmente 56.246 Mt de biomasa, que junto con 19.051 Mt importadas y 272 Mt de origen desconocido, generan una disponibilidad de 75.569 Mt. De esta cantidad, 47.237 Mt van al sistema alimentario, 518 Mt a la elaboración de biomateriales y $27.814 \mathrm{Mt}$ se pierden o tienen un destino desconocido. De las procesadas, $4.351 \mathrm{Mt}$ se exportan. Todos estos valores se expresan en forma de materia seca. Es evidente que tenemos una biomasa residual que podría ser valorizada. Para poder tener una visión del futuro debemos profundizar en el grupo de los productos químicos que se están obteniendo en la actualidad a partir de esta materia prima.

\section{LAS POSIBILIDADES DE TRANSFORMACIÓN DE LA BIOMASA}

El destino de la mayor parte de los recursos biológicos procedentes de la actividad agrícola, ganadera, pesquera extractiva o de la acuicultura es el consumo humano. Directa o indirectamente, tras una preparación, o tras una transformación más o menos intensa, se convierte en alimentos que van al consumidor. No obstante, el destino de todos estos recursos de origen biológico puede ser otros diferentes. En la Figura 2 recogemos una síntesis de las posibilidades de utilización en el marco de la bioeconomía. Es posible extraer diferentes compuestos con un elevado valor añadido, que pueden ir a los sectores de la nutrición especializada o la farmacia. También pueden transformase en bioplásticos y biopolímeros, o productos químicos a granel, o 
biocombustibles. La última opción es transformar esos recursos en energía o calor si no hubiese posibilidades de utilizarlo de otra manera.

Figura 2. Posibilidades de utilización de la biomasa en el marco de la bioeconomía

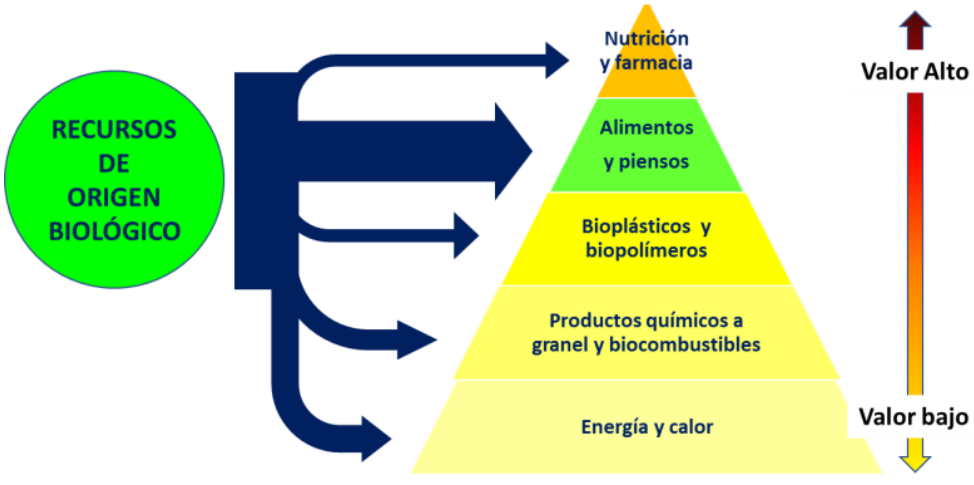

Tal y como se muestra en la figura, a medida que se va bajando en la pirámide el valor de los productos obtenidos es menor. Por ello, en la utilización de la biomasa se aplica el principio de utilización en cascada, procedente del ámbito de la valorización de los residuos: extraer de la biomasa, en primer lugar, los ingredientes o productos que tengan mayor valor.

La producción de alimentos ha sido la actividad tradicional de la bioeconomía. En el campo alimentario las posibilidades de desarrollo e innovación de este sector son ilimitadas. Las mencionaremos, aunque no entraremos en ellas en esta revisión. Las clasificaremos en función del objetivo que persiguen:

- Responder a la diversidad y diferenciación de la demanda de los consumidores, en diferentes mercados, culturas, valores, conveniencias, experiencias, grupos de edad, necesidades nutricionales 0 incluso compromisos sociales.

- Responder a los retos sociales en materia de sostenibilidad ( circularidad de procesos, huellas ambientales, bioplásticos, ecodiseños, etc), de seguridad 
alimentaria (con reducción de alergenos o toxicidades específicas de determinados grupos, tecnologías como blockchain o presiones y nuevos materiales o aditivos que pueden, a su vez alargar la vida útil), o de nutrición y salud (incorporando funcionalidad en algunos ingredientes, o nuevos ingredientes con funcionalidades adicionales, o reduciendo el empleo de determinados componentes)

- Mantener la relación coste /calidad /servicio que les permite ser un sector dinámico y competitivo en el mercado nacional y en el exterior tienen la oportunidad de trabajar en el ámbito organizativo, en la integración de nuevas tecnologías, tanto clásicas -biotecnología, nanotecnología o ecología- como emergentes - automatización, robótica, sensórica. Inteligencia Artificial-, o en la mejora de la conservación de alimentos, con diferentes combinaciones de temperatura, presión o incorporación de aditivos.

Vamos a centrar más la atención en las posibilidades de transformación de las biomasas en productos diferentes a los alimentos, siguiendo la revisión de. Iffland et al (2015). Como señalaban este mismo equipo en otro documento similar (Aeschelmann et al, 2017), es posible la obtención de cualquier derivado del petróleo a partir de biomasa, utilizando diferentes rutas metabólicas. En este resumen hemos tenido en consideración también los trabajos de BIOPLATSUSCHEM (2017), Pietrowsky et al (2018), Parisi et al (2018), Villarán et al (2018), OCDE (2018), JRC (2019) y Patinha Caldeira et al, 2020. Los derivados que podemos obtener los clasificaremos en varios grupos:

- Combustibles:

- Biometano, o biogás $(\mathrm{CH} 4)$ se crea mediante procesos microbianos anaerobios, a partir de diferentes materias primas (carbohidratos, grasas y proteínas).

- Bioetanol: se obtiene mediante diferentes procesos, materias primas y microorganismos, que pueden utilizar azúcares C5/C6. El etanol también se puede obtener mediante procedimientos anaerobios. 
- BTL (Biomasa a líquido) es un combustible sintético que se obtiene mediante un proceso en varias fases que se inicia con una pirólisis.

- Biodiesel: se genera mediante una reacción de transesterificación a partir de diferentes fuentes de triglicéridos de origen vegetal o animal, que incluyen aceite de soja, colza o palma. Es un sustitutivo del diésel derivado del petróleo.

- Aceites combustibles de origen vegetal: determinados aceites vegetales pueden adicionarse directamente en el diésel utilizado por los vehículos de motor. En teoría pueden utilizarse directamente como gasolina.

- Aceites vegetales hidro tratados: es un producto que procede de aceites vegetales hidrogenados, que puede considerarse similar al biodiesel, pero con una vida útil más larga.

- Compuestos químicos básicos (buildings blocks).

- Ácido acético: es un compuesto básico para la producción de PVA (polivinil acetato), cuando reacciona con el etileno para formar monómeros de acetato de vinilo. Los procesos para su obtención son variados, aunque suelen basarse en una fermentación acidogénica.

- Ácido láctico: se produce a través de procesos de fermentación de la biomasa. Es la base para la formación de ácido poliláctico (PLA), que puede reemplazar al poliestireno de origen fósil.

- Ácido succínico: es un producto intermedio del ciclo de ácido cítrico y un producto final del metabolismo anaeróbico de la glucosa.

- 1,3-propanediol (PDO): se puede obtener a partir de la fermentación del glicerol o usando la glucosa como materia prima. Se puede utilizar como material base para la elaboración de fibras PIT (tereftalatos de politrimetileno).

- 1,4-butanediol (BDO): es otro importante químico básico al poder reemplazar al etilenglicol en la obtención del termoplástico polibutileno tereftalato (PBT). Se puede obtener a partir del ácido succínico o mediante fermentación de azúcares con E. coli. 
- 5.Hidroximetilfurfural (HMF): se produce a partir de la deshidratación de azúcares como la fructosa y glucosa. Es un producto intermedio muy versátil a la hora de sintetizar polímeros, ofreciendo varias posibilidades. Por ejemplo, se puede utilizar para producir ácido furandicarboxílico (FDCA), que, a su vez, se puede emplear para sustituir el PET en botellas, poliamidas, poliuretanos, termoestables y plastificantes.

- Etileno: este monómero se puede obtener por la fermentación de la glucosa produciendo etanol, que después se deshidrata mediante catálisis. También se ha obtenido a partir de la fermentación de materiales lignocelulósicos.

- Monoetilenglicol (MEG): es un compuesto básico para la fabricación de polímeros como el PEF y el PET. También se puede utilizar solo, por ejemplo, para descongelar aviones o como agente de transferencia de calor. Se puede sintetizar a partir de la biomasa por varias vías, por ejemplo, a partir del etileno, vía glucosa y etanol.

- Isopreno: Se pueden usar varias materias primas para formar isopreno de base biológica, por ejemplo, glicerol, CO2 o glucosa con varios microorganismos. En la industria química se usa como material de partida para obtener goma, pesticidas o neumáticos. Además, junto con el ácido acrílico de base biológica, se puede hacer reaccionar para dar ácido tereftálico, que es uno de los monómeros utilizados en la síntesis de PET.

- Ácido acrílico: Se puede producir a partir de glicerol, como un subproducto de la obtención de biodiésel. Se puede utilizar para formar ácido poliacrílico, que es un componente importante en adhesivos y recubrimientos. Además, puede formar varios copolímeros.

- Ácido 2,5-furandicarboxilico (FDCA): Se puede obtener por oxidación del HMF. Tiene una estructura muy similar al ácido tereftalato, uno de los monómeros usados para la obtención del PET, lo que permite obtener su análogo furano, el PEF. 
- Para-xyleno (pX): SE obtiene a partir del HMF, provocando su reacción con etileno. Es un building block importante tanto para la producción de poliéster. A su vez, la oxidación del p-xileno da lugar al ácido tereftálico, que es un precursor importante del PET.

- Ácido tereftálico (TPA): se puede obtener a partir de P-xileno, o con ciclo adición de ácido acrílico e isopreno de origen biológico. El TPA es uno de los monómeros utilizados para fabricar, entre otros compuestos, los siguientes polímeros: Poli (tereftalato de trimetileno) (PTT), que se utiliza principalmente en fibras textiles; PBT (= poli (tereftalato de butileno)), un polímero técnico para aplicaciones especiales; PET (tereftalato de polietileno), utilizado en envases como botellas.

- Materiales para la producción de biopolímeros:

- Polietileno: la polimerización del etileno permite la obtención de polietileno

- Polibutileno succinato (PBS): Se puede obtener mediante varias técnicas de polimerización a partir de 1,4-butanediol y ácido succínico. Es un poliéster con propiedades mecánicas comparables al polipropileno, pero es biodegradable. Además, tiene posibilidades termoplásticas y puede ser combinado con otros polímeros como PLA, cambiando sus propiedades.

- Ácido Poliláctico (PLA): Se produce principalmente mediante la formación del dímero de lactida y la posterior polimerización por apertura de anillo. El PLA es un poliéster termoplástico alifático con una amplia gama de aplicaciones (por ejemplo, artículos de servicio de alimentos, fibras tejidas y no tejidas, impresión 3D) y se puede procesar con el equipo estándar de la industria petroquímica.

- Polihidroxialkanoatos (PHA): se puede obtener mediante fermentación utilizando gran cantidad de sustratos (glucosa, maltosa o sacarosa, por ejemplo). Es un poliéster, con características 
diferenciales en función de la longitud de las cadenas, pudiendo ser termoplástico o elastomérico.

- Poliamidas o nylons: se pueden obtener a partir del aceite de ricino.

- Furanoato de Polietileno (PEF): Utiliza como monómero el 2,5-FDCA e incluso el otro monómero etilenglicol puede ser reemplazado por BDO para crear un nuevo polímero, el PBF. Puede reemplazar el PET en productos como botellas; tienen mayor estabilidad térmica, pero, a la vez, un menor punto de fusión, por lo que puede ser procesado a bajas temperaturas.

- Tereftalato de polietileno (PET), elaborado a partir de los buildings blocks, es un biopolímero bien conocido, por su utilización para la elaboración de botellas y fibras.

- Polímeros obtenidos a partir de celulosa y almidón. La celulosa suministra la estructura a las plantas, por lo que es muy estable, mientras que el almidón es un material de reserva. Ambos están compuestos, básicamente, por glucosa: no obstante, mientras el almidón se rompe fácilmente en glucosa, en el caso de la celulosa y la hemicelulosa hay uniones con ácidos fenólicos y grupos acetilo que lo dificultan, siendo necesaria la intervención de determinadas bacterias y hongos para romper los enlaces dentro de estos materiales. A partir de ahí se pueden obtener:

- Celulosas puras, que son la base para la producción de fibras (Rayon, Modal, Lyocel) y films (celofán o esponjas)

- Derivados de celulosas, cuyos éteres se usan como aditivos o viscosantes, o los éteres que pueden ser usados como espumas termoplásticas y composites o materiales compuestos.

- Polímeros elaborados a partir de almidón.

- Alquil glucósidos, con acción tensioactiva: la reacción de la glucosa con alcoholes de cadena larga. El resultado es un producto con capacidad para formar emulsiones combinando fases oleosas y acuosas. 
- Lubrificantes y aceites hidráulicos: los aceites vegetales podrían ser utilizados con ese objetivo.

- Compuestos activos, que pueden ser extraídos para su empleo como ingredientes y aditivos en la industria alimentaria fundamentalmente, aunque también pueden ir a la farmacia o a la agroindustria. La gama de ingredientes con actividad funcional que podemos encontrar es inmensa, por lo que sólo haremos referencia a grandes grupos de productos:

- Carotenoides, que son los pigmentos de color rojo, amarillo, anaranjado o púrpura de las frutas y los vegetales, que se dividen en carotenos y xantofilas. Tienen aplicaciones en nutrición especializada y farmacia por prevenir la fotosensibilidad, el daño genético y las transformaciones neoplásicas.

- Compuestos fenólicos y flavonoides: han mostrado una gran variedad de actividades biológicas, como antioxidantes, antimicrobianas, antinflamatorias, inmunomoduladora, antiviral, anti proliferativa, anti mutagénica, vasodilatadora o preventiva de enfermedades coronarias y neurodegenerativas.

- Inulina, con sus efectos prebióticos, mejorando la absorción intestinal de minerales, disminuyendo el riesgo de arterioesclerosis.

- Glucosinatos, como metabolitos de las brasicáceas, con efecto preventivo en cáncer de colon.

- Derivados de vegetales obtenidos mediante biofermentación de subproductos de origen agrícola, utilizando microorganismos y biocatalizadores (otros microrganismo y enzimas) que dan lugar a un fluido del que se extraen productos purificados. Los productos finales que se pueden obtener son de diversa naturaleza. Haremos referencia a algunos grupos:

- Enzimas o catalizadores biológicos responsables de diversos procesos metabólicos. Algunos ejemplos de enzimas obtenidas son: amilasa, lignocelulasa, pectinasa, tanasa, proteasa, lipasa o invertasa. 
- Ácidos orgánicos, que pueden ser utilizados en distintos sectores (alimentario, farmacéutico, energético, industrial; etc). utilizando algunas especies de hongos o bacterias se han obtenido ácido láctico o ácido cítrico.

- Otros productos. no hemos mencionado otros usos de las biomasas que suelen ser destinos frecuentes, pero que podrían ser mejorados mediante la incorporación de tecnologías de procesado y preservación. Haremos referencia a dos de ellos:

- Alimentos para animales. En general suele ser un destino habitual de muchas biomasas vegetales. Sin embargo, no se someten a tratamientos de estabilización y conservación, para preservar sus ingredientes.

- Fertilizantes. Muchas biomasas, tanto vegetales como animales, se destinan a fertilizantes. De nuevo, aparece una oportunidad para transformar estos subproductos en biofertilizantes específicos para determinadas producciones o áreas concretas.

\section{LAS TECNOLOGÍAS DISPONIBLES PARA LA TRANSFORMACIÓN DE LAS BIOMASAS}

En el apartado anterior hemos comprobado amplia tipología de biomasas que podemos encontrar. Pero, además, dentro de cada tipología dispondremos de productos heterogéneos, tanto en su origen como en su tamaño, contenido en humedad, densidad o uniformidad. A veces, puede contener materiales inertes no aprovechables. Todo ello va a dificultar la recogida, transporte y manipulación. Como consecuencia, el aprovechamiento de todas estas materias primas requerirá de pretratamientos y transformaciones para acondicionarlas y facilitar su valorización. Entre ellos destacan la reducción del tamaño, la reducción de la humedad y la densificación, y la eliminación de componentes no deseados. 
En la Figura 3 recogemos un resumen, no exhaustivo, de las tecnologías que pueden ser aplicadas a la valorización de biomasas en el marco de la bioeconomía. Hemos hecho referencia a algunos de los tratamientos físicos iniciales para, a continuación, enumerar los tratamientos de extracción física, los enzimáticos, los biológicos, químicos y termoquímicos. Las fuentes utilizadas para la elaboración de este resumen han sido House of Lords (2014), Villaran et al (2018), OECD (2018), BIOPLAT (2017) y Patinha Caldeira et al (2020).

Aplicando el principio de utilización en cascada la primera opción a aplicar sería la obtención de bioproductos con algún tipo de funcionalidad. Las posibilidades que se abren son las tradicionales, basadas en la maceración y extracción en frío o en caliente con solventes, en los que es frecuente el uso de solventes verdes, tipo agua o etanol o los denominados Natural Deep Eutectic Solvents. En ocasiones se mejoran los rendimientos con la incorporación de ultrasonidos o microondas. La compresión en frío también se usa en la obtención de aceites.

Para reducir el consumo de solventes, y mejorar la eficiencia de los procesos, implantan otras tecnologías como el uso de fluidos supercríticos, como el dióxido de carbono, la extracción con pulsos eléctricos o el agua subcrítica. Otras opciones disponibles son las presiones negativas de cavitación, que permiten la extracción de polifenoles, alcaloides, polisacáridos o flavonoides. Estas técnicas que son eficientes a nivel de laboratorio pueden tener dificultades económicas cuando se pretenden escalar al ámbito industrial.

Figura 3. Resumen de las tecnologías a utilizar para el desarrollo de la bioeconomía 


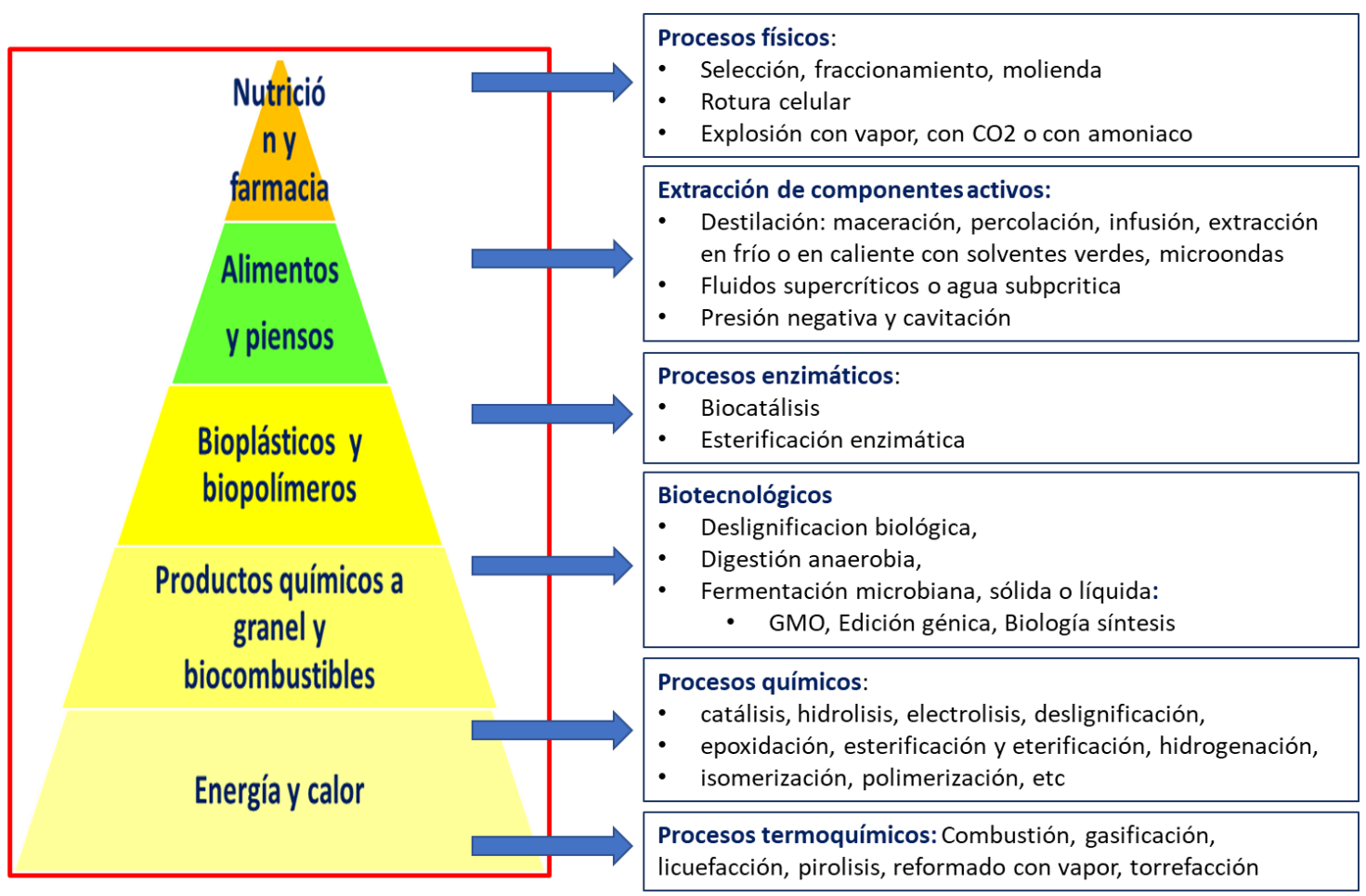

Otra vía para la obtención de derivados de la biomasa es someter la materia prima a procesos de fermentación microbiana. Sin embargo, con frecuencia, se requiere romper las paredes celulares para facilitar la acción de los microorganismos y mejorar su eficiencia. En este caso se aplican procesos físicos o físico químicos como la presión o la explosión con vapor, CO2 o amoniaco; por ejemplo, en el caso del vapor se inyecta vapor saturado a alta presión (0,7 a $5 \mathrm{MPa}$ ), aumentando la temperatura $\left(160-260^{\circ} \mathrm{C}\right) \mathrm{y}$, tras unos minutos o segundos, se reduce la presión repentinamente y la biomasa sufre una desestructuración acompañada por la degradación de la hemicelulosa y una parte importante de la lignina. La mezcla obtenida se puede someter a un tratamiento de hidrólisis, con exceso de agua en presencia usualmente de un catalizador, mediante el cual se pueden hidrolizar polisacáridos presentes en la biomasa liberando azucares C5 y C6, junto con sus isómeros y oligómeros.

La siguiente fase es la aplicación de biotecnologías que, a temperaturas y velocidades bajas, y con la acción de microorganismos y/o enzimas específicas degradan el sustrato fermentable de la biomasa. Mediante fermentación pueden transformarse aquellas materias primas que contienen un 
gran porcentaje de carbohidratos, bien en forma simple o bien en forma de polímeros de almidón o polisacáridos de celulosa y hemicelulosa. En la fermentación aeróbica, uno de los principales productos obtenidos es el bioetanol, pero, además, es posible producir una gran variedad de productos que son especialmente interesantes en la industria: xilitol, ácido succínico, ácido itacónico, lisina, 1,3-propanodiol, etc. El otro proceso bioquímico, la digestión anaeróbica, ocurre en ausencia de oxígeno y la biomasa se descompone en una suspensión acuosa de productos sólidos y productos gaseosos conocidos como biogás, usado para electricidad o energía térmica. Este proceso de transformación puede aplicarse sobre cualquier tipo de biomasa, especialmente en aquellas con un alto contenido en humedad.

La mejora de la eficiencia en los procesos biotecnológicos pasa, en muchas ocasiones, por la disponibilidad de poblaciones microbianas adaptadas a la fermentación de determinados sustratos, así como por la utilización de enzimas de acción precisa. Por ello, las tecnologías de modificación genética, de edición génica o de biologías de síntesis, son esenciales para mejorar los resultados técnicos de los procesos.

En ocasiones las biomasas se someten a un proceso de compostaje para la obtención de un biofertilizante. Consiste en la descomposición aeróbica (con oxígeno) de residuos orgánicos como restos vegetales, animales, excrementos y purines, por medio de la reproducción masiva de bacterias aerobias termófilas que están presentes en forma natural en cualquier lugar. Posteriormente, la fermentación la continúan otras especies de bacterias, hongos y actinomicetos. Si se avanza en los procesos de degradación de la materia orgánica podemos llegar a obtener un humus, que también se destina a la producción de abono.

En los procesos de fermentación se obtienen los productos primarios: buildings blocks o biogás. En el primer caso, serán necesario aplicar tecnologías bioquímicas para avanzar en la síntesis de bioderivados que tendrán salida en el mercado. Algunas de las reacciones serán las de esterificación, eterificación o transesterificación. 
Otra vía de valorización es la utilización de procesos termoquímicos, que implican una descomposición térmica de los componentes de la biomasa y una liberación de energía en forma de calor $u$ obtención de biocombustibles intermedios. Hay dos procesos termoquímicos principales que transforman la biomasa lignocelulósica en energía y productos químicos asociados a las instalaciones de biorrefinerías: la gasificación y la pirólisis. En el primer caso proceso la biomasa es oxidada parcialmente a alta temperatura (habitualmente en el rango de $600-900^{\circ} \mathrm{C}$ ) transformándose mayoritariamente en una mezcla gaseosa compuesta por $\mathrm{CO}, \mathrm{CO} 2, \mathrm{~N} 2, \mathrm{CH} 4, \mathrm{H} 2$ y H2O en distintas proporciones, dependiendo de la tecnología empleada y del agente gasificante. El segundo es una degradación térmica de biomasa en ausencia de oxígeno, en la que se genera gas de síntesis para combustible, bioaceites, carbón activo e hidrocarburos ligeros (principalmente olefinas y parafinas).

\section{RETOS Y OPORTUNIDADES DE LA BIOECONOMÍA}

Las limitaciones al desarrollo de proyectos empresariales en el ámbito de la bioeconomía se concretan tres ámbitos: en la logística del aprovisionamiento, en las dificultades tecnológicas y en los costes comparativos de la transformación de los recursos de origen fósil frente a los de origen biológico.

Las necesidades logísticas para la concentración de los subproductos y residuos. Las descripciones de las biomasas realizada nos indica que, salvo en el caso de los residuos sólidos urbanos y en los lodos de depuradora, el resto de las materias primas están dispersas en el territorio. En el caso de los residuos de origen agrícola y ganadero este hecho es especialmente relevante. En todos los casos contamos con recursos que tienen limitada concentración energética $y$, con frecuencia, elevados porcentajes de humedad. Por todo ello, la logística de la recogida y el transporte hasta un lugar de concentración en el que abordar los procesos de extracción de ingredientes funcionales o transformación en nuevos bioproductos tiene un coste económico que eleva los costes de producción finales. 
Las dificultades tecnológicas se concentran en determinadas categorías de biomasas, especialmente las que contienen elevados niveles de lignocelulosa. Los problemas técnicos que rodean la conversión de biomasas lignocelulósicas en bioproductos, han demostrado ser tan insolubles que solo un puñado de estas biorrefinerías se han vuelto comercialmente viables y la mayoría de ellas siguen siendo instalaciones con problemas (OECD, 2018). De acuerdo con esta publicación, alrededor del $40-60 \%$ del costo operativo total de una biorrefinería típica está relacionado con las materias primas elegidas. Sin embargo, el costo más significativo de los biocombustibles celulósicos de segunda generación puede ser la conversión de biomasa leñosa en azúcares fermentables.

Este explica por qué el desarrollo de las biorrefinerías de primera generación, que utilizaban como materias primas recursos que se pueden destinar a la alimentación humana (cereales, maíz, caña de azúcar aceite de soja o aceite de palma) fue muy rápido, mientras que el de las de segunda generación (residuos de cosechas, productos forestales, RSU, etc) está siendo más limitado.

Kircher (2019) ha analizado las oportunidades de la bioeconomía, dedicando un capítulo completo de su trabajo a comparar los costes de la transformación de recursos de origen biológico con los de origen fósil. Indica que la complejidad y los costos de procesamiento son un obstáculo competitivo real. Los combustibles fósiles y los productos químicos básicos se producen simplemente refinando aceite mineral o procesando gas natural (metano). Al mismo tiempo, hay que considerar la eficiencia de los procesos, tanto en términos técnicos como en términos de mano de obra: mientras el carbono de las materias primas fósiles se convierte casi por completo en el producto de destino; en el caso de los procedentes de las biomasas la eficiencia de carbono de estos procesos es menor; además la intensidad del trabajo, en los primeros, es baja en comparación con los segundos. 
Para ilustrar sus conclusiones muestra un análisis comparativo del número de pasos necesarios en cada una de las vías de producción de dos productos concretos (etanol y etileno), obtenidos a partir de recursos fósiles o a partir de recursos biológicos. Además, distingue entre las categorías de biomasas utilizadas, según contengan elementos lignocelulósicos o no. La conclusión es que se necesitan más eslabones para obtener los mismos productos, lo que explica tanto la complejidad técnica como la intensidad de la mano de obra y, al final el coste de producción.

Todo ello le permite concluir a Kircher (2019) que la competitividad de todos estos productos dependerá del precio del petróleo y del precio de la biomasa. Por tanto, podemos concluir que con un precio del barril de petróleo bajo será difícil promover el desarrollo de la bioeconomía, si solo se tienen en consideración los aspectos económicos y de mercado.

No obstante lo anterior, hemos de tener en cuenta las oportunidades relacionadas con cada uno de los retos.

- En cuanto a la logística y el aprovisionamiento hemos de recordar las políticas que se van a imponer en España y en la UE en los próximos años, para reducir los residuos generados o para transformarlos y valorizarlos, de manera que, de tener esta consideración para pasar a ser materias primas secundarias, fomentando la sinergia industrial. La presión legal forzará a la utilización de estos recursos.

- En cuanto a las tecnologías hemos de considerar que el conocimiento relacionado con la química del petróleo se ha desarrollado en los últimos 120 años, y ha permitido una innovación sistemática, haciendo posible disponer de una enorme gama de productos que satisfacen nuestras necesidades. La ciencia y la innovación en bioeconomía tiene una historia mucho más corta: en torno a unos 20 años. Por tanto, el desarrollo de una bioeconomía eficiente requiere de una ampliación de los conocimientos y su traslado al mercado a través de la innovación. En la actualidad, en la UE y en España hemos contado y, vamos a seguir 
disponiendo, con herramientas para financiar la generación del conocimiento y la innovación. En concreto señalaremos las siguientes:

- La UE ha contado con el $8^{\circ}$ Programa Marco de Investigación e Innovación, H2020, que ha contado con un área específica de financiación de la bioeconomía, tanto para generación de conocimiento como para promoción de la innovación. En este marco ha habido una iniciativa de colaboración público-privada (Biobased Industries), centrada en la bioeconomía, que ha financiado 118 proyectos en los últimos 6 años, y que cuenta con un presupuesto de $3.700 \mathrm{M} \epsilon$. En el próximo periodo de programación, en el marco de Horizonte Europa, se anuncia un incremento de la financiación general y el mantenimiento de esta iniciativa público-privada. Para el próximo periodo de programación, la estrategia de la granja a la mesa, que se incluye dentro del Green Deal, hace referencia a la financiación de la bioeconomía como una de las prioridades a tener en consideración.

- El plan Nacional de $|+D+|$ español no recoge programas específicos sectoriales; sin embargo, ha incorporado, hasta ahora, como prioridades, la generación de conocimiento y la innovación en el área de la bioeconomía. Tanto en las convocatorias de la Agencia Estatal de Investigación como en las del CDTI, la bioeconomía se ha consolidado como la segunda área de investigación e innovación a la hora de captar recursos, después de la de salud. En el futuro Plan Nacional es previsible que la bioeconomía siga teniendo un papel importante, a tenor de las prioridades de la UE. Por otra parte, los programas de desarrollo rural han incluido, hasta ahora, la financiación de proyectos que impulsen el desarrollo de la bioeconomía como uno de sus objetivos importantes. 
- A nivel CCAA todas las RIS3 han considerado la bioeconomía como estratégica, con un mayor o menor sesgo hacia la producción primaria y la transformación agroalimentaria. Por ello los programas para financiar la innovación con cargo a los fondos de desarrollo regional han estado abiertos a financiar esta área de actividad.

- Los productos biobasados, con un coste de producción superior, tendrán dificultades para competir en un contexto de mercados abiertos. Sin embargo, hemos de tener en consideración una serie de hechos:

- Las tendencias de la demanda y, especialmente, de la distribución, que está promoviendo su diferenciación en el mercado a través de la oferta de productos con menor impacto en emisiones de GEl.

- Las políticas europeas, que van a estimular el etiquetado de todo tipo de productos incorporando alegaciones que hagan referencia a la sostenibilidad del proceso productivo, considerando toda la cadena de valor. Las emisiones de GEl y la huella de carbono van a tener un lugar predominante en esas etiquetas y es claro que los productos biobasados tienen menos huella de carbono.

- Una de las partidas que mayor impacto tiene en el coste de producción de cualquier producto industrial es el de la amortización de la inversión, en la que los costes financieros son especialmente relevantes. La inversión en proyectos para desarrollar la bioeconomía va a ser especialmente priorizados en los próximos años, tanto en el ámbito europeo como a nivel nacional.

\section{7. el anÁlisis del CICLO de VIDA COMO PRESUPUESTO PARA EL DESARROLLO DE PRODUCTOS}


La bioeconomía europea se ha construido sobre los principios de la eficiencia y la sostenibilidad (Lainez et al, 2018; Lainez y Periago, 2019). Por ello, pretende el máximo aprovechamiento de las biomasas pero, a la vez, considera que el uso de los recursos debe garantizar su disponibilidad para las futuras generaciones. Por otra parte, la bioeconomía surge como alternativa al uso de los recursos fósiles, no renovables, para mitigar las consecuencias del uso sistemático de este tipo de recursos, siendo las más importante el cambio climático. Por tanto, cualquier proyecto de valorización de las biomasas debe venir acompañado de una reducción de los impactos, y especialmente, de la huella de carbono del producto final obtenido, obteniendo ventajas comparativas respecto al mismo producto derivado de materias primas de origen fósil.

Kircher (2019), en su revisión de la bioeconomía muestra ejemplos en los que la huella de carbono de los productos bio es sensiblemente menor que los derivados de origen fósil. No obstante, también demuestra que la obtención de biocombustibles y biopolímeros, en las condiciones consideradas en los ejemplos que utiliza, no se pueden conseguir sin huellas de gases de efecto invernadero (GEI). Las emisiones son generadas sobre todo por la agricultura y el procesamiento. El uso de energías renovables es más efectivo en el procesamiento. Por lo tanto, concluye, que los inversores que confían en procesos y productos bioderivados deben analizar cuidadosamente la fuente de materia prima y la intensidad energética de un proceso en particular y examinar las posibilidades de integración del proceso en sistemas energéticos libres de emisiones.

La utilización de la biomasa para diferentes propósitos es fomentada y respaldada por políticas y estrategias de bioeconomía nacionales y globales, como consecuencia de esa premisa de que la obtención de biodegradados va a generar menos gases de efecto invernadero que sus homólogos de origen fósil. Dado que la bioeconomía puede verse como una solución para estos desafíos globales, también puede tener impactos adversos en el medio ambiente, en términos de degradación de la tierra, pérdida de biodiversidad y 
disminución de la capacidad para brindar servicios ecosistémicos, que deben analizarse (Pursula et al 2018).

Moldan et al (2012) a la hora de describir la sostenibilidad ambiental consideran seis grandes áreas a tener en cuenta dentro de este concepto:

- Sistemas climáticos (que cubren el clima y el cambio climático, el clima, la gestión de riesgos, mitigación y adaptación).

- Asentamientos humanos y hábitats (que cubren ciudades, urbanización y transporte).

- Sistemas de energía (que cubren el uso de energía, la conservación de energía, energías renovables, eficiencia energética y bioenergía).

- Sistemas terrestres (que abarcan ecosistemas naturales y gestionados, silvicultura, sistemas alimentarios, biodiversidad y servicios de los ecosistemas).

- Ciclos de carbono y nitrógeno (cubriendo fuentes y sumideros, retroalimentación procesos y enlaces a otros sistemas).

- Sistemas acuáticos (que abarcan ecosistemas marinos y de agua dulce, pesca, corrientes y biodiversidad).

Desde el punto de vista científico se han hecho muchas aproximaciones para medir la sostenibilidad. Sin embargo, en la actualidad se considera que la manera más objetiva de analizar la sostenibilidad de los procesos productivos es la utilización del análisis de ciclo de vida.

El análisis del ciclo de vida de un producto es una herramienta de caracterización de las huellas ambientales integrales de los productos y los sistemas productivos. Se percibe como una herramienta clave para garantizar una transición hacia patrones de producción y consumo más sostenibles. Tal y como señalan Notarmicola et al (2016) y Holden et al (2018), el pensamiento del ciclo de vida se utiliza cada vez más para evaluar la sostenibilidad de los sistemas.

Es un enfoque utilizado para evaluar los productos, procesos o servicios en términos de su lugar en el mundo, del ciclo de vida completo que se requiere 
para que sirvan a la sociedad y al medio ambiente y las consecuencias sociales y económicas de ese servicio. El método ha sido reconocido como el enfoque líder para incluir la sostenibilidad en la toma de decisiones en los Estados Unidos (NRC, 2014), Europa (JRC, 2012) y en otras partes del mundo. La herramienta cuantitativa utilizada para implementar el pensamiento del ciclo de vida es la evaluación del ciclo de vida (LCA), que está formalizada por la norma internacional (ISO 14040/14044).

El JRC ha estado trabajando para definir unos estándares de aplicación del LCA en diferentes cadenas de valor de la bioeconomía. Los análisis realizados muestran una alta variabilidad en los resultados publicados (Cristóbal et al, 2016). Los estudios individuales revisados difieren entre sí con respecto a varios supuestos metodológicos: definición de los límites del sistema, unidad funcional, recuperación de energía, emisiones de carbono y métodos de almacenamiento y asignación. Todas estas diferencias influyen considerablemente en el resultado ambiental y la interpretación general y la comparación de los resultados se vuelven bastante complejos. Además, se ha observado una baja uniformidad en la forma en que se presentan los resultados. Todas estas cuestiones destacan la gran necesidad de armonización y coherencia metodológicas para el LCA de las cadenas de valor de la bioeconomía. Similares conclusiones han obtenido Martin et al (2018)

\section{EL IMPACTO DE LA BIOECONOMÍA EN DIFERENTES SECTORES}

El JRC mantiene actualizados los datos de la importancia de la bioeconomía en la Unión Europea y en cada uno de los Estados Miembros, en su Knowledge Bioeconomy Center. Los últimos datos disponibles corresponden a 2017. En España, la bioeconomía generó en 2017 un volumen de ventas de 219 millones de $€$, que se corresponde con un valor añadido de 65 millones $€$. Además, dio empleo a 1,42 millones de personas. Podemos observar que el sector agrario y alimentario en España son muy importantes, tanto en términos de empleo (81\%) como en términos de valor añadido en el conjunto de la bioeconomía (78\%). 
Sorprende que algunos sectores, como el de la electricidad de origen biológico apenas se ha desarrollado en nuestro país.

Los resultados específicos para cada uno de los subsectores que integran la bioeconomía española se presentan en la Tabla 1. Se muestran los porcentajes que representa cada uno de los subsectores, en términos de empleo y de valor añadido, así como el valor añadido por persona ocupada en cada uno de los sectores. La conclusión más evidente que podemos extraer de esta información es que el peso específico de la bioeconomía española sigue estando soportado por los sectores clásicos. Los sectores de los químicos de origen biológico y los bioplásticos se han desarrollado menos, al igual que ha ocurrido con la electricidad de origen bio o los biocombustibles líquidos.

Tabla 1.- Comparación de la población ocupada, el valor añadido y el valor añadido por persona ocupada en los diferentes sectores de la bioeconomía en la España en 2017

(Elaboración propia a partir de KBC, 2020)

\begin{tabular}{|l|c|c|c|}
\hline & $\begin{array}{c}\% \\
\text { Población } \\
\text { ocupada }\end{array}$ & $\begin{array}{c}\text { \% Valor } \\
\text { añadido }\end{array}$ & $\begin{array}{c}\text { Valor } \\
\text { añadido/persona } \\
\text { ocupada ( } € \text { ) }\end{array}$ \\
\hline Agricultura & 52,4 & 45,9 & 40.287 \\
\hline Alimentos y bebidas & 28,7 & 32,2 & 51.709 \\
\hline Madera y mueble & 5,7 & 4,1 & 33.487 \\
\hline Papel & 3,2 & 5,2 & 75.317 \\
\hline Textiles Bio & 3,2 & 2,2 & 31.638 \\
\hline Producción forestal & 1,3 & 1,5 & 55.899 \\
\hline $\begin{array}{l}\text { Químicos bio y } \\
\text { plásticos }\end{array}$ & 2,6 & 5,7 & 102.415 \\
\hline Pesca y acuicultura & 2,9 & 2,5 & 39.732 \\
\hline Electricidad bio & 0,1 & 0,3 & 100.919 \\
\hline $\begin{array}{l}\text { Biocombustibles } \\
\text { líquidos }\end{array}$ & 0,0 & 0,3 & 474.216 \\
\hline
\end{tabular}

Pietrowsky et al (2018) hacen un análisis de la bioeconomía en Europa. Además de los grandes datos sectoriales, describen la importancia de las diferentes clases de compuestos químicos originados a partir de las biomasas. Con esos datos elaboramos la Tabla 2, en la que incluimos la importancia que 
tienen cada uno de esos grupos de químicos, que nos da una orientación sobre los sectores que se van a poder beneficiar de los mismos.

Tabla 2.- Importancia de las clases de productos químicos biobasados producidos en Europa (elaboración propia a partir de Pietrowski et al, 2018)

\begin{tabular}{|l|c|}
\hline Clases de productos & \% sobre el total \\
\hline $\begin{array}{l}\text { Productos básicos (building } \\
\text { bloks) }\end{array}$ & 35,1 \\
\hline Fertilizantes & 33,3 \\
\hline Polímeros & 5,4 \\
\hline Detergentes & 5,4 \\
\hline Aceites vegetales & 3,6 \\
\hline Adhesivos & 3,6 \\
\hline Fibras & 3,2 \\
\hline Pinturas & 0,9 \\
\hline Colorantes y pigmentos & 0,5 \\
\hline Agroquímicos & 0,3 \\
\hline Otros químicos biobasados & 8,7 \\
\hline
\end{tabular}

El JRC ha realizado un análisis del estado de la situación, tanto tecnológica como de mercado, de productos biobasados centrado en los siguientes grupos: productos químicos básicos, solventes, polímeros para plásticos, pinturas, recubrimientos, tintas y tintes, tensioactivos, cosméticos y productos de cuidado personal, adhesivos, lubricantes, plastificantes (y estabilizadores para caucho y plásticos) y fibras artificiales. A partir de una lista de 350 productos se seleccionaron 50. Se llevó a cabo una evaluación detallada del mercado de los seleccionados, que cubría la producción en la UE, el precio, el volumen de negocios, el consumo, el comercio, el uso de materias primas y los requisitos de tierras agrícolas. Sobre la base del análisis de los 50 productos, se recopiló información de mercado sobre las categorías de productos, que cubría la producción y la cuota de mercado de la UE, la dependencia de las importaciones de la UE, el tamaño futuro del mercado, la inversión privada, la importancia de los Estados miembros y la UE a producción, nivel de madurez y un análisis DAFO. (Spekreijse et al, 2019) 
Es un documento de interés para consultar tanto una categoría como un producto concreto. En el caso de las categorías se presenta una hoja resumen del conjunto de la información recopilada.

El Boston Consulting Group elaboró en 2018 una Guía de bioeconomía circular para CEOs en la que estiman el impacto de la bioeconomía, a nivel global en 7,7 billones de USD entre 2018 y 2030 (BCG, 2019). Desde su punto de vista genera oportunidades empresariales para:

- Crear nuevos mercados, accediendo a nuevos segmentos de consumidores, desarrollando nuevas cadenas de valor.

- Proporcionar a las empresas un negocio con menor impacto ambiental, atrayendo otro tipo de talento y nuevos consumidores.

- Mitigar los riesgos regulatorios a los que se van a enfrentar las empresas en las áreas del cambio climático y la gestión de residuos, poniendo a las empresas a la vanguardia de la sostenibilidad reclamada por la sociedad.

En este trabajo también se identifican los sectores en los que se prevé un incremento más sustancial de las oportunidades de negocio relacionadas con la bioeconomía. Para cada uno de ellos se estima el crecimiento del mercado ligado a la bioeconomía, en miles de millones de dólares, entre 2018 y 2030. También se hace una referencia a los materiales en los que se va a basar ese crecimiento. A continuación, los repasamos:

- Sector de la bioenergía y los biocombustibles. Se prevé que pasará de 150 a 200, con especial atención a la bioenergía solida incluyendo los pellets de madera obtenidos a partir de subproductos y los biocombustibles líquidos, incluyendo el biodiesel, el biometano, el etanol de origen celulósico y los combustibles renovables "directos".

- Residuos de alimentos, para los que se estima un crecimiento de 2.300 a 2.600, en los que se hace mención a la reutilización de residuos, reciclaje de nutrientes orgánicos y tejidos de seda, satén y viscosa de piel de naranja. 
- Sector farmacéutico, en el que se prevé un crecimiento de 250 a 750, concretando algunas áreas como las vacunas a partir de plantas medicinales, los tratamientos frente al cáncer con compuestos sintetizados a partir de sustancias vegetales o la tecnología blockchain asociada a la producción de proteínas como base para tratamientos médicos.

- Sector textil, con un incremento del valor desde los 400 a los 700, en los que se consideran fibras de alta tecnología, fibras obtenidas a partir de biomasas y residuos biológicos, textiles compostables entre los que se menciona el Locel.

- Sector de la construcción y materiales de construcción, en el que se estima un incremento de 350 a 700, para estructuras a base de madera, estructuras circulares, los composites reforzados con fibras naturales, o materiales aislantes de base biológica.

- Sector del envase y el embalaje, con un crecimiento esperado de 400 a 500, en el que los productos identificados son el papel y cartón de embalaje flexible reciclable, el embalaje de papel que sustituye a los plásticos (por ejemplo, cartón de embalaje para bebidas), los bioplásticos reciclables y las mezclas de almidón y plástico biodegradables.

- Sector de vehículos a motor y componentes, en los que se prevé pasar de 250 a 550, identificando como productos las fibras naturales como piezas de los coches, el revestimiento interior compostable a base de bioplásticos y los neumáticos a base de diente de león en sistema de circuito cerrado.

- Sector de otros productos forestales, para el que se estima un crecimiento de 150 a 200, recogiéndose como ejemplos de productos los bio lubricantes o los aditivos basados en enzimas.

- En el sector de la maquinaria y equipos prevén un crecimiento del mercado de 50 a 100, incluyendo como ejemplos la ingeniería de bioprocesos e ingeniería agrícola. 
También merece una atención especial el Informe McKinsey y cambio climático (2020) en el que se hace referencia a las posibilidades de desarrollos de algunos sectores concretos, con gran dedicación al transporte, tanto automóvil como aéreo.

\section{CONCLUSIONES}

La promoción de la economía circular, la descarbonización de la economía o la mitigación del cambio climático son grandes estrategias de trabajo, impulsadas desde las políticas europeas y desde muchos países, incluido España, que van a promover el desarrollo de la bioeconomía en los próximos años.

En España se estima una producción de 27.814 Mt de materia seca de biomasas residuales que se pierde o tiene un destino desconocido.

La producción de recursos biológicos ha tenido como objetivo tradicional la obtención de alimentos para cubrir las necesidades de las personas. Además de seguir suministrando alimentos, la bioeconomía puede hacer uso de las biomasas residuales para obtener una gran diversidad de productos, entre los que se incluyen los compuestos químicos básicos o building bloks, los materiales para la obtención de biopolímeros, los compuestos activos, los derivados de la biofermentación o los combustibles.

Hay un gran abanico de tecnología disponibles para la valorización de biomasas, cuya eficiencia se está mejorando continuamente, que incluyen procesos físicos, procesos de extracción de componentes activos, procesos biotecnológicos, químicos y termoquímicos.

Los retos para el desarrollo de la bioeconomía son la logística del aprovisionamiento, las dificultades tecnológicas y los costes comparativos de la transformación de los recursos de origen fósil frente a los de origen biológico. Frente a ellos, las oportunidades van a venir generadas por los cambios en la percepción social de la importancia de la sostenibilidad, que se va a traducir en una modificación de las pautas de la demanda de la distribución. Además, 
las políticas europeas, especialmente las derivadas del Pacto Verde, van a limitar el acceso al mercado de determinados productos tradicionales y, a la vez, apoyar la inversión para el desarrollo de proyectos de la bioeconomía.

El desarrollo de estos proyectos debe ser abordado garantizado la sostenibilidad ambiental de la inversión y del proceso productivo. La herramienta para poder realizar este análisis de los impactos será el análisis del ciclo de vida.

El desarrollo de la bioeconomía se va a producir como consecuencia de la puesta en el mercado de productos en nuevos sectores económicos en los que, hasta ahora, la presencia de los bioproductos no ha sido importante. Destacan los sectores de la gestión y valorización de residuos, especialmente los alimentarios, los de ámbito farmacéutico, los del textil, los de la construcción y materiales de construcción, los del envase y el embalaje, los de vehículos a motor y componentes, los de la bioenergía y los biocombustibles, otros productos forestales y de la maquinaria y equipos

\section{REFERENCIAS}

BCG (2019). CEO Guide to the Circular Bioeconomy. Recuperado de: https://www.wbcsd.org/Programs/Circular-Economy/Factor10/News/Leading-companies-endorse-WBCSDs-call-for-a-strongercircular-bioeconomy.

Bioplat suschem, (2017). Manual sobre las biorrefinerías en España. Recuperado de:

file:///C:/Users/mlain/Desktop/bioval/Manual-sobreBiorrefiner\%C3\%ADas-en-Espana-Feb-2017.pdf.

CAMIA, A., ROBERT, N., JONSSON, R., PILLI, R., GARCÍA-CONDADO, S., LÓPEZLOZANO, R., VAN DER VELDE, M., RONZON, T., GURRÍA, P., M'BAREK, R., TAMOSIUNAS, S., FIORE, G., ARAUJO, R., HOEPFFNER, N., MARELLI, L. \& GIUNTOLI, J., Biomass production, supply, uses and flows in the European 
Union. First results from an integrated assessment, EUR 28993 EN, Publications Office of the European Union, Luxembourg, (2018), ISBN 97892-79-77237-5, doi:10.2760/539520, JRC109869.

CARROL, M. \& DAMMER, L. (2018). The "Circular Bioeconomy" - Concepts, Opportunities and Limitations. Nova paper \#9 on bio-based economy 2018-01.

COM (2019) 640 final Comunicación de la Comisión al Parlamento Europeo, al Consejo Europeo, al Consejo, al Comité Económico y Social Europeo y al Comité de las Regiones el Pacto Verde Europeo. Recuperado de: https://eur-lex.europa.eu/legalcontent/EN/TXT/?aid=1588580774040\&uri=CELEX:52019DC0640.

COM, (2020) 98 final. Nuevo Plan de acción para la economía circular por una Europa más limpia y más competitiva (EUR-Lex - Access to European Union law - choose your language (europa.eu)).

CRAMER, W., GUIOT, J., FADER, M., GARRABOU, J. \& GATTUSO, JP. (2018). Climate change and interconnected risks to sustainable development in the Mediterranean. Nature Climate Change, Nature Publishing Group, 2018, 8 (11), pp.972 - 980. ff10.1038/s41558-018-0299-2ff. ffhal-01911390.

CROWLE, T.J. (2000). Causes of Climate Change Over the Past 1000 Years. Science $289,270-277$.

EIB 2020 Circular Economy Guide - Supporting the circular transition. Recuperado de: https://www.eib.org/attachments/thematic/circular economy guide e n.pdf.

European Commission (2020). The EU Blve Economy Report. 2020. Recuperado de:

https://ec.europa.eu/maritimeaffairs/sites/maritimeaffairs/files/2020 06_b lueeconomy-2020-ld final.pdf.

GURRIA, P., RONZON, T., TAMOSIUNAS, S., LOPEZ, R., GARCIA CONDADO, S., GUILLEN, J., CAZZANIGA, N. \& M'BAREK, 2017. "Biomass flows in the European Union: The Sankey biomass diagram - towards a cross-set 
integration of biomass, JRC Working Papers JRC106502, Joint Research Centre (Seville site).

HAMELIN, L., BORZĘCKA, M., KOZAK, M. \& PUDEŁKO, R. (2019). A spatial approach to bioeconomy: Quantifying the residual biomass potential in the EU-27, Renewable and Sustainable Energy Reviews. Renewable and Sustainable Energy Reviews. Volume 100, February 2019, Pages 127-142.

HOLDEN, N., WHITE, E.P., LANGE, M,C. \& OLDFIELD, T.L. (2018) Review of the sustainability of food systems and transition using the Internet of Food. Science of Food (2018) 2:18; doi:10.1038/s41538-018-0027-3.

IDEA (2011).

Recuperado

de: https://www.idae.es/uploads/documentos/documentos_11227_e15_resi duos_c3ead071.pdf.

IFFLAND, K., SHERWOOD, J., CARUS M., RASCHKA, A., FARMER, T. \& CLARK, J. 2015: Definition, Calculation and Comparison of the "Biomass Utilization Efficiency (BUE)" of Various Bio-based Chemicals, Polymers and Fuels, Hürth 2015-11. Download at www.bio-based.eu/nova-papers.

JRC European Commission - Joint Research Centre. (2012). Life cycle indicators framework: development of life cycle based macro-level monitoring indicators for resources, products and waste for the EU-27. European Commission, Joint Research Centre, Institute for Environment and Sustainability.

KBC. Knowledge Bioeconomy Center (2020). Bioeconomy I Knowledge for policy (europa.eu). Acceso 7 de diciembre de 2020.

KIRCHER, M. (2019). Bioeconomy: Markets, Implications, and Investment Opportunities. Economies 2019, 7, 73; doi:10.3390/economies7030073.

KRAUSMANN, F., GINGRICH, S., EISENMENGER, N., ERB, K., HABERL H. \& FISCHERKOWALSKI M. (2009). Growth in global materials use, GDP and population during the 20th century. Ecological Economics 68(10), 2696-2705. Doi: 10.1016/j.ecolecon.2009.05.007.

KRAUSMANNA, F., WIEDENHOFERA, D., LAUKA, K., HAASA, W., TANIKAWAB, H., FISHMANB, T., MIATTOB, A., SCHANDLD, H. \& HABER, H. (2017) Global 
socioeconomic material stocks rise 23-fold over the 20th century and require half of annual resource use. PNAS February 21, 2017114 (8) 18801885; https://doi.org/10.1073/pnas.1613773114.

LAINEZ, M. \& PERIAGO, M.J. (2019). The Bioeconomy: An Opportunity for the Spanish Economy. Chapters, in: Krzysztof Biernat (ed.), Elements of Bioeconomy, IntechOpen. Doi: 10.5772/intechopen.84917.

LAINEZ, M., PERIAGO, M.J., ARRIBAS, N. \& MENESES, C. (2018). La bioeconomía como oportunidad para la economía española: la visión desde el observatorio de bioeconomía. Mediterráneo económico, n 31, 95-118. Recuperado

de:

https://www.publicacionescajamar.es/publicacionescajamar/public/pd f/publicaciones-periodicas/mediterraneo-economico/31/mediterraneoeconomico-31.pdf.

M'BAREK, R., PHILIPIDIS, G., SUTA, C., \& SANTINI, F. (2014). Observing and analyzing the Bioeconomy in the EU - Adapting data and tools to new questions and challenges. Bio-based and Applied Economics 3(1): 83-91, 2014. Doi: 10.13128/BAE-14189.

MCKINSEY (2020), Mckinsey on climate change. September 2020. Recuperado de: https://www.mckinsey.com/.

MOLDAN, B., JANOUŠKOVÁ, S. \& HÁK, T. (2012). How to understand and measure environmental sustainability: Indicators and targets. Ecological Indicators. Volume 17, June 2012, Pages 4-13.

NOTARMICOLA, B., TASIELLI, G., RENZULLI, P.A., CASTELLANI, V. \& SALA, S. (2017). Environmental impacts of food consumption in Europe. Journal of Cleaner Production 140 (2017) 753e765.

NRC. (2014). Sustainability and the U.S. EPA. Committee on Incorporating Sustainability in the U.S. Environmental Protection Agency. Science and Technology for Sustainability Program. Policy and Global Affairs Division. National Research Council of the National Academies. ISBN 978-0-30921252-6. The National Academies Press. 2014. 
OCDE. (2018). Growing a sustainable Bioeconomy Bio-production for the biennium 2015-2016. DSTI/STP/BNCT(2016)1. Recuperado de: http://www.oecd.org/.

PARISI, C. (2018). "Research Brief: Biorefineries distribution in the EU". European Commission - JRC.

PATINHA CALDEIRA, C., VLYSIDIS, A., FIORE, G., DE LAURENTIIS, V., VIGNALI, G. \& SALA, S. (2020). Sustainability of food waste biorefinery: A review on valorisation pathways, techno-economic constraints, and environmental assessment, BIORESOURCE TECHNOLOGY, ISSN 0960-8524 (online), 312, p. 123575, JRC118963.

PIOTROWSKI, S., CARUS, M. \& CARREZ, D. (2018). European Bioeconomy in Figures 2008-2015. Comissioned by Biobased Industries Consortium. Recuperado de:

https://biconsortium.eu/sites/biconsortium.eu/files/documents/Bioecono my data 2015 20150218.pdf.

PURSULA, T., AHO, M., RÖNNLUND, I. \& PÄÄLLYSAHO, M. (2018) Environmental Sustainability Indicators for the Bioeconomy. En Leal, Roberto y Borges Eds. Towards a Sustainable Bioeconomy: Principles, Challenges and Perspectives. Pag 43 -62. Springer International Publishing AG 2018.

RONZON, T., PIOTROWSKI, S., TAMOSIUNAS, S., LARA, D., CARUS, M. \& M’BAREK, R. (2020). Developments of Economic Growth and Employment in Bioeconomy Sectors across the EU. Sustainability 2020, 12, 4507; doi:10.3390/sul2114507.

SCARLAT, N., DALLEMAND, JF. \& FAHL, F. (2018). Biogas: Developments and perspectives in Europe. Renewable Energy 129: 457-472. https://doi.org/10.1016/j.renene.2018.03.006.

SPEKREIJSE, J., LAMMENS, T., PARISI, C., RONZON, T. \& VIS, M. (2019) Insights into the European market of bio-based chemicals. Analysis based on ten key product categories, EUR 29581 EN, Publications Office of the European Union, Luxembourg, 2019, ISBN 978-92-79-98420-4, doi:10.2760/549564, JRC 112989. 
https://publications.jrc.ec.europa.eu/repository/bitstream/JRC112989/jirc _europeanmarket_biochemicals_online.pdf

THORENZ, A, WIETSCHEL, L., STINDT, D. \& TUMA, A. (2018). Assessment of agroforestry residue potentials for the bioeconomy in the European Union. Journal of Cleaner Production.Volume 176, 1 March 2018, Pages 348-359

UE. (2019). Causes of climate change. Recuperado de: https://ec.europa.eu/clima/change/causes en.

VILLARÁN, M.C., CHAVARRI, M., DIETRICH, T. \& RODRIGUEZ, E. (2018). Subproductos hortofrutícolas para una bioeconomía circular. Mediterráneo económico, $n^{\circ}$ 31, 251- 272. Recuperado de: https://www.publicacionescajamar.es/publicacionescajamar/public/pd f/publicaciones-periodicas/mediterraneo-economico/31/mediterraneoeconomico-31.pdf. 